\title{
COMPREHENSIVE ASSESSMENT OF REGIONAL SUSTAINABILITY VIA EMERGY, GREEN GDP AND DEA: A CASE STUDY IN GUIZHOU PROVINCE, CHINA
}

\author{
YI, Q. G. ${ }^{1,2}-$ CHEN, H. T. ${ }^{1}-$ LI, X. ${ }^{3 *}-$ MA, C. ${ }^{4}$ \\ ${ }^{1}$ School of economics, Guizhou university of finance and economics, Guiyang 550025, China \\ ${ }^{2}$ Western institute of green development strategy of China, Guiyang 550025, China \\ ${ }^{3}$ School of Management Science and Engineering, Guizhou university of finance and economics, \\ Guiyang 550025, China \\ ${ }^{4}$ School of Big Data Application and Economics, Guizhou university of finance and economics, \\ Guiyang 550025, China \\ *Corresponding author \\ e-mail:361740439@qq.com; phone: +86-181-8515-3106; fax:+86-851-8851-0571
}

(Received $5^{\text {th }}$ Sep 2020; accepted $30^{\text {th }}$ Nov 2020)

\begin{abstract}
We propose a comprehensive eco-efficiency framework based on emergy theory, green gross domestic product (GGDP) and data envelopment analysis (DEA) to get a thorough assessment of regional sustainability. The paper evaluates the sustainable development of Guizhou Province from 2000 to 2017 based on emergy analysis, GGDP and DEA. Moreover, the GGDP, which has deducted the undesirable output, is selected as the output index to calculate the eco-efficiency of Guizhou Province and further evaluate its sustainable development level by the super-SBM model. The results showed that the growth rate of the GGDP in Guizhou Province was far lower than that of the GDP. The proportion of the GGDP in GDP showed a trend of continuous decline from $78.32 \%$ to $60.60 \%$ mainly due to the high consumption of non-renewable resource products. Moreover, there were seven effective years during 2000-2017. There was redundancy in capital input and labor input, and the input and output were not optimal in the ineffective years. Therefore, we suggest that Guizhou Province should achieve technological progress by introducing talents, perfect industrial layout, optimize the industrial structure, and gradually realize the transformation industry from high energy consumption, high emission and high pollution to low energy consumption, low emission and low pollution.
\end{abstract}

Keywords: eco-efficiency, green gross domestic product (GGDP), emergy analysis, super-SBM, undesirable output

\section{Introduction}

It is necessary to measure and evaluate the regional sustainable development status comprehensively to realize sustainable development. At present, the evaluation methods widely accepted and applied include ecological footprint, emergy analysis, emergy ecological footprint (Zhao et al., 2005), green GDP (He et al., 2016), comprehensive evaluation method (Cabello et al., 2014), etc. Eco-efficiency has been put forward as an index to analyze sustainable development (Schaltegger and Burritt, 2000), that is, the ratio of the value of services and products to the environmental impact. Its core idea is to exchange the maximum economic value with the minimum resource consumption and environmental pollution degree (Scholz and Wiek, 2005). The accounting methods of eco-efficiency can be summarized into three types: single ratio method, index system method and model method (Mandal, 2010; Victor et al., 2017; Yue et al., 2020). The three accounting methods have their advantages and disadvantages. The model method 
mainly includes the ecological footprint method, data envelopment analysis (DEA) and some extension models of DEA (Hua et al., 2007; Yin et al., 2014; Li et al., 2019; Ren et al., 2020), while DEA has been widely used in recent years due to its unique advantages. Firstly, DEA requires relatively little information. Secondly, it does not need dimensional processing of original input-output data. Finally, it directly assigns weights to the indexes without the need to determine the weights artificially, which overcomes the influence of subjective factors on the results. At present, the theory of eco-efficiency has been constantly developed and improved and has been applied in many research fields (Kim et al., 2018; Xiang et al., 2020) with the integration of other methods, such as emergy analysis (EMA) (Wu et al., 2018; Cao et al., 2019), ecological footprint (He et al., 2016), life cycle assessment (LCA) (Park et al., 2016; Masuda, 2019), etc.

DEA model for accounting eco-efficiency needs to determine the inputs and outputs. Heretofore, gross domestic product (GDP) is the key indicator of output (Yin et al., 2014; Robaina-Alves et al., 2015). GDP did not consider the resources and environment loss cost, there are differences in the selection of undesirable outputs, and some pollutants in the discharge of "three wastes" are usually selected as the undesirable output (Li et al., 2019; Wang et al., 2020). The processing methods of undesirable output are different, such as undesirable output as an input method, reciprocal conversion method, directional distance function method and modified DEA model. The results of the different studies could not be compared. When evaluating regional eco-efficiency based on DEA model, most studies take GDP as the desirable output (Jin et al., 2014). But GDP ignores the depletion of resources and damage to the environment in the process of economic growth. As a supplement and improvement to GDP, GGDP refers to the GDP after deducting the value of resource consumption and environmental pollution loss, which overcomes the disadvantage of GDP not considering resource and environmental factors (Talberth and Bohara, 2006; Boyd, 2007). "Although some studies stated that the GGDP should be used in future regional-scale eco-efficiency measurements, these kinds of studies are few, especially in China" (He et al., 2016). He et al. (2016) used DEA model to evaluate the eco-efficiency of Jiangsu Province and took GGDP as the output. However, unreasonably, they still took pollutant emission which has been deducted from GGDP as undesirable output. In addition, for ease of calculation, they changed the nature of undesirable output by taking it as an input.

In order to make up for the above deficiencies and accurately evaluate the regional sustainability, the holistic eco-efficiency method has been built by aggregating emergy analysis (EMA), DEA and GGDP into an improved framework. By taking GGDP as the output after deducting undesirable output, the paper provides a theoretical basis for sustainable development decision making in Guizhou Province and a new way of thinking for a comprehensive evaluation of regional sustainable development level. This study aimed to comprehensively evaluate the sustainable development level of Guizhou Province by the new ecological efficiency framework and put forward suggestions for improvement.

\section{Methodology and methods}

\section{Study area}

Guizhou Province, with its fragile ecological environment and large mountainous area, is an important ecological barrier in the upper reaches of the Yangtze River and the Pearl River (Figure 1). At present, it faces major ecological problems such as soil 
erosion, forest degradation, biodiversity reduction and water resources shortage. Under the background that the country attaches importance to the development of the west and further deepens the development of the west, the actual situation of the underdeveloped areas in China requires the region to develop its economy according to its own resource advantages in the future, so as to realize the regional sustainable development. Therefore, as an inland open economic pilot zone, it is particularly important to ensure the sustainable development of Guizhou. This paper made a preliminary evaluation of the sustainable development level of Guizhou Province with combined emergy and GGDP accounting, then used DEA to calculate the eco-efficiency. The research results can be used for reference in other areas.

$$
\text { The location of Guizhou Province, China Guizhou Province }
$$

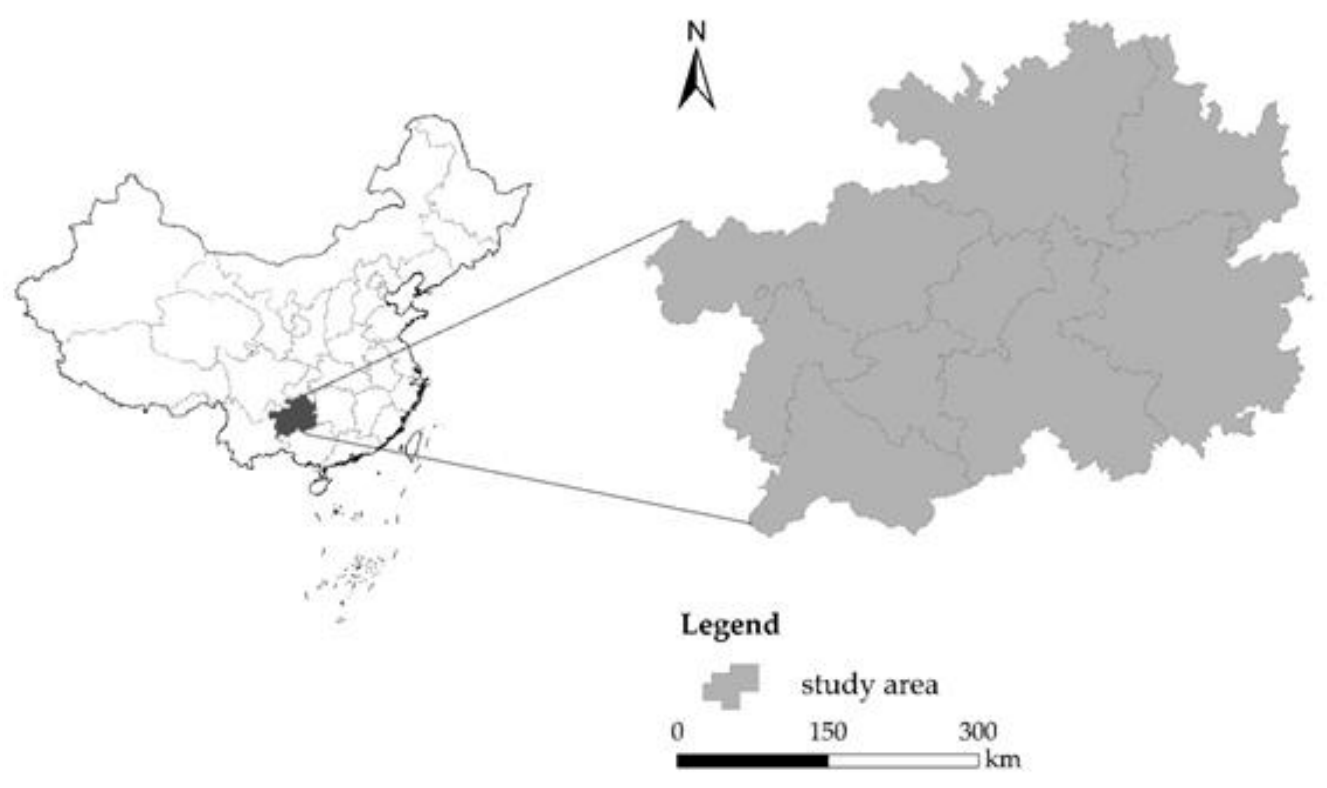

Figure 1. The location of Guizhou Province, China

\section{Emergy analysis}

The concept of emergy was proposed in the 1980s by Odum (1988), a famous American ecologist. It has been widely used by scholars to study and evaluate an urban ecological economic system, agricultural ecosystem and marine ecosystem (Odum, 1996, 2000; He et al., 2016; Wu et al., 2018; Cao et al., 2019). The solar emergy of each product and resource is calculated as follows:

$$
E=M \times T
$$

where $E$ is the emergy (sej); $M$ is the available energy (J); $T$ is the transformity of a product or a resource.

Emergy indicators can be used to comprehensively evaluate the sustainable development ability of the system based on emergy theory. Emergy evaluation indicators are shown in Table 1. 
Table 1. Emergy evaluation indicators for Guizhou

\begin{tabular}{c|c}
\hline Indicators & Expression \\
\hline Renewable Resources & $\mathrm{R}$ \\
Nonrenewable Resources & $\mathrm{N}$ \\
Imports & $\mathrm{IMP}$ \\
Exports & EXP \\
Total Emergy Used & $\mathrm{U}=\mathrm{R}+\mathrm{N}+\mathrm{IMP}-\mathrm{EXP}$ \\
Emergy Yield Ratio (EYR) & $\mathrm{EYR}=(\mathrm{R}+\mathrm{N}+\mathrm{IMP}) / \mathrm{IMP}$ \\
Environmental loading ratio(ELR) & ELR $=(\mathrm{U}-\mathrm{R}) / \mathrm{R}$ \\
Emergy-based sustainability index (ESI) & ESI =EYR/ELR \\
\hline
\end{tabular}

\section{GGDP accounting based on emergy analysis}

Gross domestic product (GDP) is an important indicator to measure and reflect the economic development level of a country or region. However, there are limitations in the accounting of GDP, which ignores the impact of human economic activities on resources and the environment. Green GDP (GGDP) makes up for the deficiency of GDP and includes the cost of resource consumption and environmental damage into the accounting, which can reflect the real wealth of the society and the idea of sustainable development. GGDP is calculated based on emergy analysis in the paper.

\section{Total emergy}

The core idea of emergy theory is to convert different kinds of resources or products into uniform units of emergy and then measure through solar transformity The calculation formula of the total emergy of the system is as follows:

$$
E=\sum_{i=1} E_{i}=\sum_{i=1}\left(M_{i} \times T\right)
$$

where $E$ is the total emergy of the system (sej); $E_{i}$ is the total emergy (sej) of the ith resource or product; $M_{i}$ is the raw data (sej) for the ith resource or product; $T$ is the transformity of a product or a resource.

\section{Emdollar value}

Emdollar value refers to the amount of money equivalent to the emergy of an ecoeconomic system when it is converted into money. Its calculation formula is the ratio of the emergy of resources or products to emergy/dollar ratio, namely

$$
\begin{gathered}
V_{i}=E_{i} / R \\
R=\sum_{j=1} E_{j} / G D P
\end{gathered}
$$

where $V_{i}$ is the emdollar value of the ith resource or product $(\$) ; E_{i}$ is the total emergy of the ith resource or product (sej); $R$ is emergy/dollar ratio (sej/\$); $\sum_{j=1} E_{j}$ is the sum of the total emergy utilized by the system (including renewable environmental resources, nonrenewable environment resources, nonrenewable resources products, money flows). $G D P$ is the gross domestic product (\$). 
$G G D P$

The calculation formula of GGDP is as follows:

$$
G G D P=G D P-\sum A-\sum B-\sum C
$$

where $\sum A$ is the total emdollar value of nonrenewable natural resources; $\sum B$ is the total emdollar value of nonrenewable resource products; $\Sigma C$ is the total emdollar value of waste materials. The specific indicator system is shown in Table 2.

Table 2. Emergy analysis in Guizhou Province

\begin{tabular}{|c|c|c|}
\hline Category & Item & Transformity $^{\text {a }}(\mathrm{sej} / \mathrm{J})$ \\
\hline Renewable natural resources & $\begin{array}{c}\text { Solar radiation energy } \\
\text { Rain chemical energy } \\
\text { Rain geo-potential energy } \\
\text { Wind kinetic energy } \\
\text { Earth cycle energy }\end{array}$ & $\begin{array}{c}1 \\
623 \\
15444 \\
8888 \\
29000 \\
\end{array}$ \\
\hline Nonrenewable natural resources & Topsoil loss & 74000 \\
\hline Renewable resource products & $\begin{array}{c}\text { Hydropower } \\
\text { Cereal } \\
\text { Beans } \\
\text { Potato } \\
\text { Oil plants } \\
\text { Bast fiber plants } \\
\text { Sugarcane } \\
\text { Tobacco } \\
\text { Vegetables } \\
\text { Tea } \\
\text { Fruits } \\
\text { Meat } \\
\text { Milk } \\
\text { Eggs } \\
\text { Honey } \\
\text { Aquatic products } \\
\text { Forest products } \\
\end{array}$ & $\begin{array}{c}80000 \\
148000 \\
690000 \\
83000 \\
690000 \\
83000 \\
84000 \\
84900 \\
83000 \\
200000 \\
530000 \\
4000000 \\
2000000 \\
2000000 \\
84000 \\
2000000 \\
44000 \\
\end{array}$ \\
\hline Nonrenewable resource products & $\begin{array}{c}\text { Raw coal } \\
\text { Gasoline } \\
\text { Kerosene } \\
\text { Diesel } \\
\text { Fuel oil } \\
\text { Natural gas } \\
\text { Steels } \\
\text { Cement } \\
\text { Nitrogenous fertilizers } \\
\text { Phosphatic fertilizer } \\
\text { Potash fertilizers } \\
\text { Compound fertilizers } \\
\text { Pesticides } \\
\text { Plastic membranes } \\
\end{array}$ & $\begin{array}{c}40000 \\
66000 \\
66000 \\
66000 \\
54000 \\
53000 \\
1.40 \mathrm{E}+15 \\
2.07 \mathrm{E}+15 \\
3.80 \mathrm{E}+15 \\
3.90 \mathrm{E}+15 \\
1.10 \mathrm{E}+15 \\
2.80 \mathrm{E}+15 \\
1.60 \mathrm{E}+15 \\
3.80 \mathrm{E}+14 \\
\end{array}$ \\
\hline Currency flow & $\begin{array}{c}\text { Import commodities } \\
\text { Foreign capital utilized } \\
\text { Foreign exchange earnings from tourism } \\
\text { Labor services } \\
\text { Export commodities }\end{array}$ & $\begin{array}{l}1.66 \mathrm{E}+12 \\
1.66 \mathrm{E}+12 \\
1.73 \mathrm{E}+12 \\
3.80 \mathrm{E}+05 \\
1.66 \mathrm{E}+12 \\
\end{array}$ \\
\hline Waste material & $\begin{array}{c}\text { Waste gas } \\
\text { Wastewater } \\
\text { Solid waste } \\
\end{array}$ & $\begin{array}{l}4.80 \mathrm{E}+04 \\
8.60 \mathrm{E}+05 \\
1.80 \mathrm{E}+06 \\
\end{array}$ \\
\hline
\end{tabular}

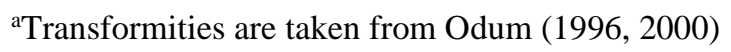




\section{DEA model}

Charnes et al. (1978) put forward the concept of Data Envelopment Analysis (DEA). The traditional CCR model and VRS model do not consider the slack of input and output. Tone (2001) proposed a non-radial and non-angular SBM model based on slack variables. However, the traditional SBM model cannot sort effective decision-making units. Based on this, Tone (2002) proposed the super- SBM model, which can effectively distinguish the conditions of effective decision units. Super efficiency SBM model is as follows:

$$
\begin{gathered}
\min \delta=\frac{\frac{1}{m} \sum_{i=1}^{m} \overline{x_{2}} / x_{i 0}}{\frac{1}{s} \sum_{r=1}^{s} \overline{y_{r}} / y_{r 0}} \\
\bar{X} \geq \sum_{j=1, \neq 0}^{n} \lambda_{j} x_{j} \\
\text { s.t. } \bar{y} \leq \sum_{j=1, \neq 0}^{n} \lambda_{j} y_{j} \\
\bar{X} \geq x_{0}, \bar{y} \leq y_{0} \\
\sum_{j=1, \neq 0}^{n} \lambda_{j}=1 \\
\bar{y} \geq 0, \lambda \geq 0
\end{gathered}
$$

where $n$ is the number of decision-making units (DMU); $m$ and $s$ are the numbers of input indicators and output indicators; $\bar{x}$ and $\bar{y}$ are the slack variables of input and output; $\lambda$ is a constant vector; If $\delta \geq 1$, DMU is said to be effective. If $\delta \leq 1$, DMU is said to be ineffective. The higher the $\delta$, the higher the ecological efficiency.

Technically and empirically, DEA has the following requirements on DMU: Firstly, DMU in the reference set should have the characteristics of the same type; Secondly, it is generally considered that the number of elements in reference set is not less than three times of the total number of input and output indicators (He et al., 2016). This paper will take Guizhou Province as the research object and carry out empirical analysis based on relevant data of Guizhou Province from 2000 to 2017, which meets the basic requirements of DEA. In the DEA efficiency evaluation process, capital stock and labor input are taken as inputs, and GGDP is taken as output. The efficiency is called green efficiency to distinguish it from traditional eco-efficiency. Among them, the capital stock is invested using the perpetual inventory method. The data calculation is based on the year 2000 and the estimation formula is:

$$
K_{t}=\left(1-\delta_{t}\right) K_{t-1}+I_{t}
$$

where $K_{t}$ is the capital stock at the end of the year; $\delta_{t}$ is the depreciation rate; $I_{t}$ is the actual investment. The investment indicator of the year is the total fixed capital formation.

Labor input is the total number of people employed at the end of each year. The desirable output is calculated by GGDP. In the calculation process, GDP is calculated based on the price of the year 2000. The GGDP has deducted the undesirable output 
such as resource loss and environmental pollution, which directly solves the problem of the undesirable output. The ecological efficiency was calculated using DEA-SLVER Pro5.0 software developed by Tone (2002).

\section{Data source}

Here we used data from 2000 to 2017 to evaluate the eco-efficiency of Guizhou Province. The basic data of renewable environmental resources, non-renewable environmental resources, renewable resource products, non-renewable resource products, monetary flow and the total number of employees employed at the end of each year were collected from the Guizhou Statistical Yearbooks 2001-2018 (which presents data from 2000 to 2017). And the basic data of waste gas, waste water and solid waste were obtained from the China Statistical Yearbooks 2001-2018. The total fixed capital formation data were collected from the National Bureau of Statistics website. The emergy calculation formula, emergy conversion coefficient and transformity used in this paper refer to the research results of Odum $(1996,2000)$ and Brown and Ulgiati (2016).

\section{Results and Discussions}

\section{Emergy analysis}

The sustainable development index of Guizhou from 2000 to 2017 was calculated to analyze the sustainability of the economic development of Guizhou Province based on emergy analysis. Emergy yield ratio (EYR) is defined as the ratio of the emergy used to the emergy input. This index is a standard to measure the production efficiency of a system. The higher the EYR is, the higher the production efficiency of the system will be. Although EYR had fluctuations in Guizhou Province, the overall declined during the past 18 years, with the maximum in 2002 and the minimum in 2017 (Figure 2). The main reason for the decrease of EYR was that the feedback input into Guizhou's economic system increased sharply, including the utilization of foreign capital and the import of resources.

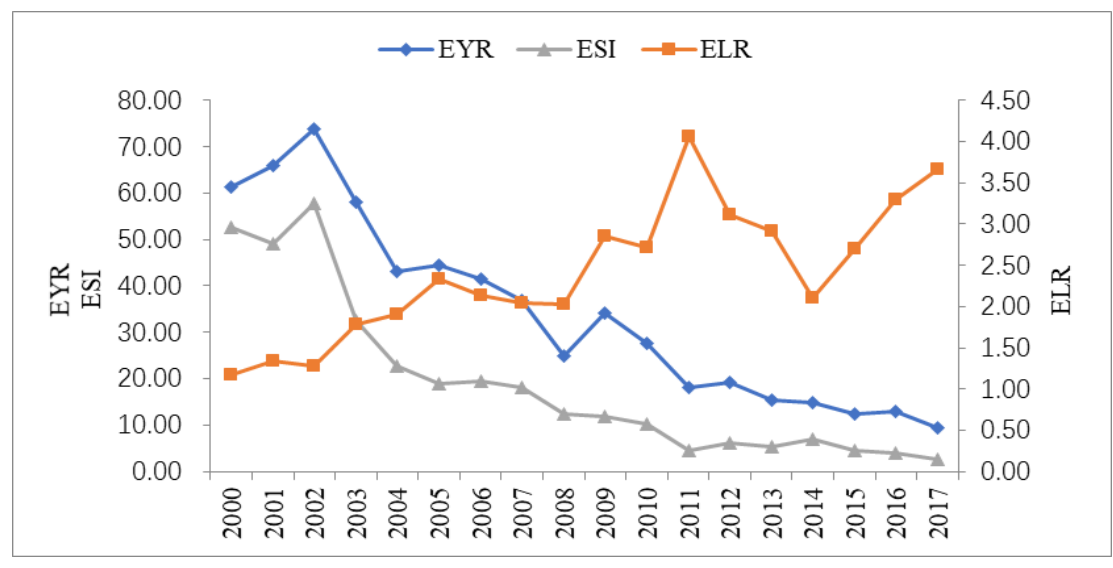

Figure 2. Trend of emergy-based indices in Guizhou Province from 2000 to 2017

Environmental loading ratio (ELR) is defined as the ratio of the total emergy of nonrenewable resources to the total emergy of renewable resources. The indicator represents the environmental pressure of the system. The higher the ELR is, the greater 
the environmental pressure of the system is. ELR increased volatility from 2000 to 2017 (Figure 2), among which ELR showed a significant decline from 2011 to 2014. However, the trend did not last long. An obvious upward trend from 2014 to 2017 indicated that the economic development of Guizhou Province put increasing pressure on the environment in recent years.

The overall change trends of EYR and ELR of Guizhou were similar to that of Changsha (Wu et al., 2018). Emergy-based sustainability index (ESI) is defined as the ratio of EYR to ELR. When ESI is between 1 and 10, it means that the economic system is dynamic and has development potential. When ESI is larger than 10, it is a sign of economic underdevelopment. When ESI is less than 1, it means that the economic system is consumption-oriented (Lei et al., 2020). The ESI and EYR was roughly the same trend (Figure 2). ESI was more than 10 before 2011 and that Guizhou Province was economically underdeveloped. After 2011, ESI was between 1 and 10. The economic system of Guizhou Province had the potential for development and there was room for improvement.

\section{Analysis of GGDP}

Guizhou Province saw a marked increase in both GDP and GGDP from 2000 to 2017 (Figure 3). The growth rate of GDP was much faster than that of GGDP in recent ten years. He et al. (2016) reported similar results that traditional GDP grew faster, while green GDP grew slower and the gap between the two was growing. The ratio of GGDP to GDP was $78.32 \%$ in 2000 , dropping to $60.60 \%$ in 2017 . The declining ratio of GGDP to GDP in Guizhou Province is mainly due to the rising emdollar value of nonrenewable resource products and wastes in recent years, especially non-renewable resource products (Figure 4). The emdollar value of non-renewable resource products surged by 16.68 times, and the emdollar value of wastes increased by 7.64 times. Raw coal was the non-renewable resource product with the largest consumption, accounting for more than half of non-renewable resource products during the study period. At the same time, solid waste accounted for more than $50 \%$ of the waste. This indicates that Guizhou Province consumed a large amount of non-renewable resource products and discharged a large amount of waste in the economic development process from 2000 to 2017. The rapid economic development came at the cost of resource consumption and environmental damage.

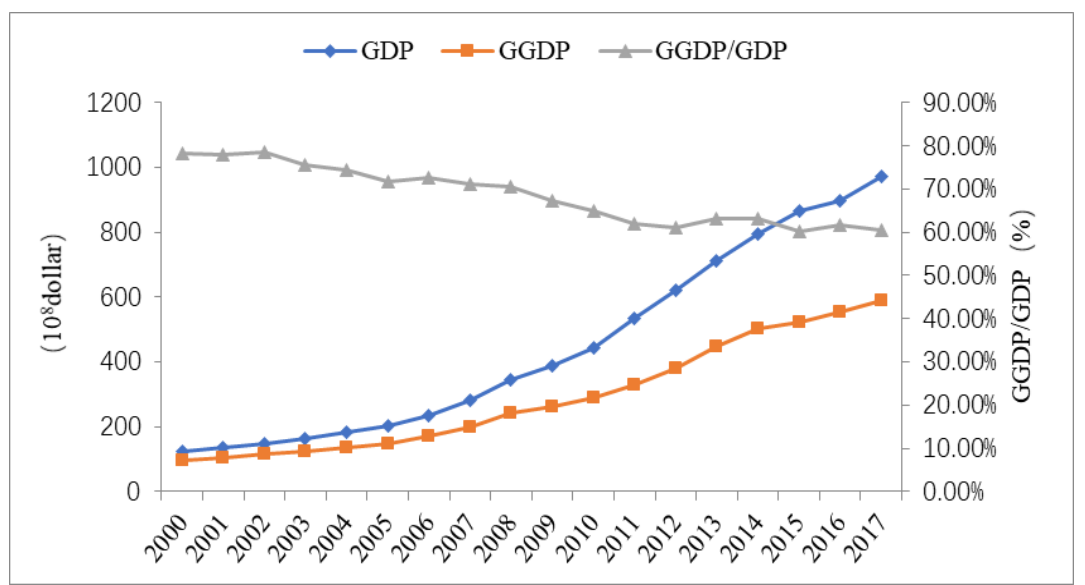

Figure 3. The trends of GDP and GGDP of Guizhou Province from 2000 to 2017 


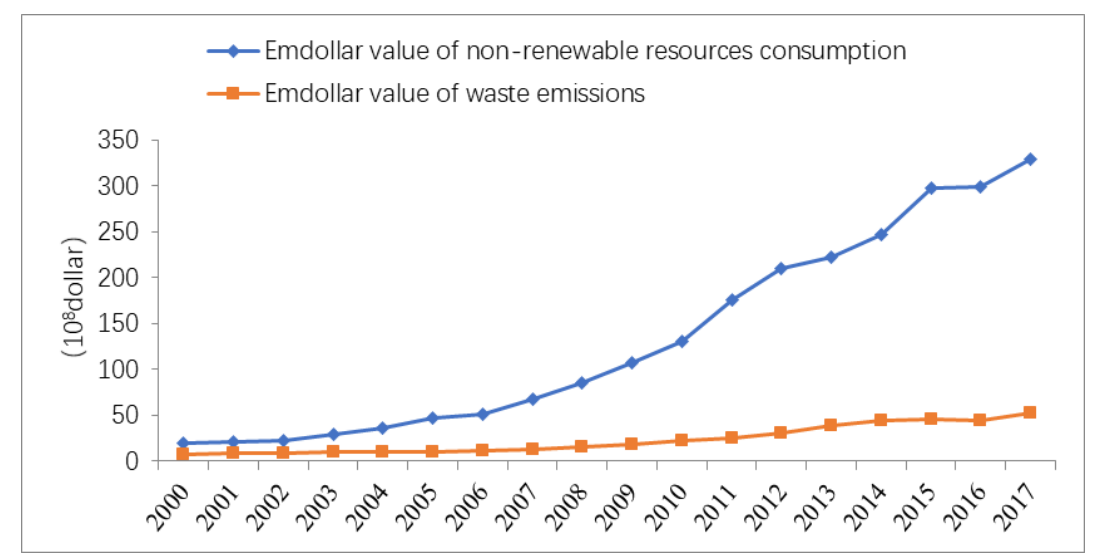

Figure 4. Emdollar value of non-renewable resources consumption and waste emissions of Guizhou Province from 2000 to 2017

\section{DEA}

We used DEA-SOLVER Pro5.0 software to calculate the eco-efficiency (green efficiency) of Guizhou Province from 2000 to 2017. The results are shown in Table 3. The average green efficiency of Guizhou Province during 2000 - 2017 was 0.986, less than 1. Both capital input and labor input were redundant, and labor redundancy was more serious than capital redundancy. There was a shortfall in economic output. During the study period, the effective years of DEA were 2000, 2008, 2010, 2011, 2013, 2014 and 2017, and their green efficiency were all greater than 1, while the remaining years were ineffective. The effective years of Guizhou Province accounted for 39\%, higher than Jiangsu Province with 20\% (He et al., 2016). The highest green efficiency was 1.132 in 2000 and the lowest was 0.887 in 2004. It can be seen that the green efficiency of Guizhou Province was lower and its performance was poor in 2000-2006. Capital input was not redundant, but labor input was relatively redundant and GGDP output was insufficient during these six years. Excessive input of labor still showed the phenomenon of insufficient output, which indicates that the economic development input of Guizhou Province in this period was mainly low-quality labor force, and the high-quality labor force was relatively scarce, which failed to realize the optimal efficiency of labor input. The redundancy of labor input had been alleviated, and the green efficiency was higher than the previous stage since 2007. In the last five years, the green efficiency in 2013 and 2014 was more than 1 and ranked high. However, in 2015 and 2016, the green efficiency declined significantly, and capital and labor input utilization were insufficient, leading to the failure of optimal allocation of input factors and output factors. Green efficiency in 2017 ranked second, efficient utilization of capital and labor force and insufficient output indicate that there was still much room for improvement in the economic development of Guizhou Province. In the future, investment in scientific and technological innovation should be increased to achieve efficient and high-quality development.

To sum up, on the one hand, Guizhou Province needs to make full use of renewable energy, such as abundant hydropower, sunlight and wind, and strictly controls the discharge of waste. On the other hand, Guizhou should improve the quality of the labor force and formulate the policy of attracting talents. Since the 2015 "Guiyang International Big Data Industry Expo" was held in Guiyang, the capital of Guizhou 
Province, the province has focused on the development of big data industry, which has brought vitality and opportunities to the economic development. Guizhou should seize this opportunity and follow a characteristic path of sustainable development based on big data. Besides, Guizhou should fully exploit rich tourism resources, focus on creating a "colorful Guizhou", and develop characteristic ecological tourism as a new economic growth point of Guizhou.

Table 3. The results of the super-SBM model of Guizhou Province from 2000 to 2017

\begin{tabular}{c|c|c|c|c|c}
\hline DMU & Score & Rank & Capital excess & Labor excess & GGDP shortage \\
\hline 2000 & 1.132 & 1 & 42.876 & 201.709 & 0.000 \\
2001 & 0.943 & 14 & 0.000 & 201.690 & 0.919 \\
2002 & 0.935 & 15 & 0.000 & 239.753 & 0.952 \\
2003 & 0.891 & 17 & 0.000 & 278.539 & 6.038 \\
2004 & 0.887 & 18 & 0.000 & 319.461 & 6.090 \\
2005 & 0.921 & 16 & 0.000 & 77.656 & 9.374 \\
2006 & 0.948 & 13 & 0.000 & 86.481 & 5.369 \\
2007 & 0.992 & 8 & 0.000 & 5.714 & 1.343 \\
2008 & 1.025 & 4 & 48.470 & 0.000 & 0.000 \\
2009 & 0.990 & 9 & 0.000 & 19.032 & 1.214 \\
2010 & 1.014 & 6 & 0.000 & 49.670 & 0.000 \\
2011 & 1.001 & 7 & 0.028 & 3.116 & 0.000 \\
2012 & 0.989 & 11 & 0.000 & 1.682 & 3.974 \\
2013 & 1.019 & 5 & 79.583 & 9.382 & 0.000 \\
2014 & 1.032 & 3 & 0.000 & 0.000 & 15.667 \\
2015 & 0.971 & 12 & 178.557 & 11.144 & 0.000 \\
2016 & 0.990 & 10 & 58.760 & 7.963 & 0.000 \\
2017 & 1.067 & 2 & 0.000 & 0.000 & 37.169 \\
Mean & 0.986 & - & 22.682 & 84.055 & 4.895 \\
\hline
\end{tabular}

The comprehensive application of multiple sustainable development evaluation methods can complement each other's advantages and make up for the weak persuasive effect of single evaluation method, which can evaluate the status of the research area more comprehensively and point out the improvement direction for enhancing the regional sustainable development ability. The green GDP accounting based on emergy theory not only measures the consumption of non-renewable resource products, but also measures the pollution loss caused by waste discharge, indicating that the economic development of Guizhou Province is based on resource consumption and environmental pollution. DEA efficiency evaluation model further points out that DEA invalid years have insufficient utilization rate of capital input and labor input.

The green GDP excluding the undesirable output is selected as the output index, which provides a new idea for DEA efficiency evaluation to solve the undesirable output problem. The following aspects can be further studied in the later stage. Firstly, only the negative effects of non-renewable resource consumption and environmental pollution loss are considered in the process of calculating green GDP based on emergy theory. Since the positive effects of resource and environment improvement in Guizhou need to be highlighted, the later stage can try to explore the accounting in this aspect. Secondly, in DEA efficiency evaluation, further research will consider technological innovation input from the perspective of $R \& D$ intelligence input and capital input. 


\section{Conclusions}

This study applied the emergy analysis theory, GGDP and super-SBM model to comprehensively calculate the sustainable development level of the study region, and analyzed the deficiencies and improvement directions in the economic development from 2000 to 2017. The GGDP with undesirable output deducted is selected as the output, which provides a new idea for DEA efficiency evaluation to solve the problem of undesirable output.

First, based on the emergy evaluation indicators of Guizhou Province, it can be concluded that the environmental loading ratio of Guizhou presented an overall trend of increase mainly due to the increasing use of non-renewable resources from 2000 to 2017, while the emergy yield ratio and emergy-based sustainability index generally presented a trend of decline. The main reasons for the decline of productivity were the large increase in the utilization of foreign capital and the import of resources.

Second, GGDP and GDP from 2000 to 2017 in Guizhou Province simultaneously rose, but the growth rate of GGDP was less than that of GDP. The proportion of GGDP in GDP had been decreasing from $78.32 \%$ to $60.60 \%$, mainly due to the dramatic increase in consumption of nonrenewable resource products and waste emissions, which had widened the gap between the GGDP and GDP.

Third, 2000-2017 was divided into two stages with 2008 as the cut-off point. The green efficiency of the second stage was higher on the whole than that of the first stage, and the ineffective years of DEA mostly fell in the first stage. There were seven years in which the green efficiency was greater than 1, that is, DEA was effective in Guizhou Province from 2000 to 2017. In the remaining eleven years, DEA was ineffective. In the ineffective years, there were redundant capital investment and redundant labor input, and the factor combination of input and output did not reach the optimal state.

Acknowledgements. This research was supported by the Natural Science Research project of Department of Education of Guizhou Province (Qian Jiao He KY Zi (2015)365), and University-level Research Fund of Guizhou University of Finance and Economics (2019XYB07). The authors are grateful to the colleague Jun-hong Zhao for helping me improve the text of this article.

\section{REFERENCES}

[1] Boyd, J. (2007): Nonmarket benefits of nature: what should be counted in green GDP? Ecological Economics 61(4): 716-723.

[2] Brown, M. T., Ugiati, S. (2016): Emergy assessment of global renewable sources. Ecological Modelling 39: 148-156.

[3] Cabello, J. M., Navarro, E., Prieto, F., Rodríguez, B., Ruiz, F. (2014): Multicriteria development of synthetic indicators of the environmental profile of the Spanish regions. Ecological Indicators 39: 10-23.

[4] Cao, L., Zhou, Z., Yi, Y., Huang, Y., Cao, G. (2019): Is metabolism in all regions of China performing well? - Evidence from a new DEA-Malmquist productivity approach. Ecological Indicators 106: 105487.

[5] Charnes, A., Cooper, W. W., Rhodes, E. (1978): Measuring the efficiency of decision making units. - European Journal of Operational Research 2(78): 429-444.

[6] He, J., Wan, Y., Feng, L., Ai, J., Wang, Y. (2016): An integrated data envelopment analysis and emergy-based ecological footprint methodology in evaluating sustainable development, a case study of Jiangsu Province, China. - Ecological Indicators 70: 23-34. 
[7] Hua, Z., Bian, Y., Liang, L. (2007): Eco-efficiency analysis of paper mills along the Huai River: an extended DEA approach. - Omega 35(5): 578-587.

[8] Jin, J., Zhou, D., Zhou, P. (2014): Measuring environmental performance with stochastic environmental DEA: The case of APEC economies. - Ecological Modelling 38: 80-86.

[9] Kim, J., Jeon, E., Cho, S., Kim, H. (2018): The promotion of environmental management in the South Korean health sector-Case study. - Sustainability 10(6): 2081.

[10] Lei, K., Wang, Z., Ton, S. (2008): Holistic emergy analysis of Macao. - Ecological Engineering 32: 30-43.

[11] Li, X., Cai, Q., Yang, X. Y. (2019): Environmental efficiency assessment and difference analysis of industrial cluster districts in China. - Applied Ecology and Environmental Research 17(4): 9035-9049.

[12] Mandal, S. K. (2010): Do undesirable output and environmental regulation matter in energy efficiency analysis? evidence from Indian cement industry. - Energy Policy 10: 6076-6083.

[13] Masuda, K. (2019): Eco-Efficiency assessment of intensive rice production in Japan: joint application of life cycle assessment and data envelopment analysis. - Sustainability 11(19): 5368.

[14] Odum, H. T. (1988): Self-organization, transformity, and information. - Science 242(4882): 1132.

[15] Odum, H. T. (1996): Environmental Accounting: Emergy and Environmental Decision Making. - John Wiley \& Sons, New York.

[16] Odum, H. T. (2000): Emergy evaluation of an OTEC electrical power system. - Energy 25: 389-393.

[17] Park, Y. S., Egilmez, G., Kucukvar, M. (2016): Emergy and end-point impact assessment of agricultural and food production in the United States: A supply chain-linked Ecologically-based Life Cycle Assessment. - Ecological Indicators 62: 117-137.

[18] Ren, W., Zhang, Z., Wang, Y., Xue, B., Chen, X. (2020): Measuring regional ecoefficiency in China (2003-2016): A "Full World" perspective and network data envelopment analysis. - International Journal of Environmental Research and Public Health 17(10): 3456.

[19] Robaina-Alves, M., Moutinho, V., Macedo, P. (2015): A new frontier approach to model the eco-efficiency in European countries. - Journal of Cleaner Production 103: 562-573.

[20] Schaltegger, S., Burritt, R. (2000): Contemporary environmental accounting: issues, concepts and practice. - Greenleaf Publishing, Sheffield, UK.

[21] Scholz, R. W., Wiek, A. (2005): Operational eco-efficiency: comparing firms' environmental investments in different domains of operation. - Journal of Industrial Ecology 4: 155-170.

[22] Talberth, J., Bohara, A. K. (2006): Economic openness and green GDP. - Ecological Economics 58(4): 743-758.

[23] Tone, K. (2001): A slacks-based measure of efficiency in data envelopment analysis. European Journal of Operational Research 130(3): 498-509.

[24] Tone, K. (2002): A slacks-based measure of super-efficiency in data envelopment analysis. - European Journal of Operational Research 143(1): 32-41.

[25] Victor, M., Mara, M., Margarita, R. (2017): The economic and environmental efficiency assessment in EU cross-country: evidence from DEA and quantile regression approach. Ecological Indicators 78: 85-97.

[26] Wang, C., Hsu, H., Wang, Y., Nguyen, T. (2020): Eco-Efficiency assessment for some European countries using slacks-based measure data envelopment analysis. - Applied Sciences 10(5): 1760.

[27] Wu, Y., Que, W., Liu, Y., Li, J., Cao, L., Liu, S., Zeng, G., Zhang, J. (2018): Efficiency estimation of urban metabolism via emergy, DEA of time-series. - Ecological Indicators 85: 276-284. 
[28] Xiang, H., Wang, Y., Huang, Q., Yang, Q. (2020): How much is the eco-efficiency of agricultural production in west China? Evidence from the village level data. International Journal of Environmental Research and Public Health 17(11): 4049.

[29] Yin, K., Wang, R., An, Q., Yao, L., Liang, J. (2014): Using eco-efficiency as an indicator for sustainable urban development: a case study of Chinese provincial capital cities. Ecological Indicators 36: 665-671.

[30] Yue, L., Xue, D., Draz, M. U., Ahmad, F., Li, J., Shahzad, F., Ali, S. (2020): The doubleedged sword of urbanization and its nexus with eco-efficiency in China. - International Journal of Environmental Research and Public Health 17: 446.

[31] Zhao, S., Li, Z. Z., Li, W. L. (2005): A modified method of ecological footprint calculation and its application. - Ecological Modelling 185: 65-75. 